\title{
SINTERING OF CERAMICS USING LOW FREQUENCY RF POWER
}

J.B.O. Caughman, D.J. Hoffman, F.W. Baity, M.A. Akerman, S. C. Forrester, and M.D. Kass

Oak Ridge National Laboratory

Oak Ridge, TN 37831-8071

\section{ABSTRACT}

Sintering with low frequency if power $(\sim 50 \mathrm{MHz})$ is a new technique with unique capabilities that has been used to sinter a variety of ceramic materials, including zirconia-toughened alumina, alumina, silicon carbide, and boron carbide. Processing with low frequencies offers many advantages compared to processing with conventional microwave frequencies ( $915 \mathrm{MHz}$ and $2.45 \mathrm{GHz}$ ). Because of the longer wavelength, the rf electric field penetrates materials more than microwaves. This effect allows the processing of a wider variety of materials and allows for an increase in the physical size of the material being processed. In addition, the material is heated in a single mode cavity with a uniform electric field, which reduces the occurrence of hot-spot generation and thermal runaway effects. This technique has been used to sinter large crack-free alumina samples ( $3 "$ square) to $>97 \%$ density. The sintering and/or annealing of a number of carbide materials has been demonstrated as well, including silicon carbide, boron carbide, tungsten carbide, and titanium carbide.

\section{INTRODUCTION}

A great deal of work has been done in the past ten years with the use of microwaves in the sintering of ceramics [1,2]. An advantage of microwave sintering over conventional sintering is related to the volumetric interaction of the electromagnetic fields with the ceramic. This volumetric coupling to the ceramic leads to a higher heating efficiency and faster processing times than those achievable in conventional furnaces. However, because of its small penetration depth, microwave sintering is mostly limited to materials with relatively small volumes and/or low dielectric loss tangents.

The heating of the ceramic is obtained by the coupling of the electric field with the dielectric losses of the material. The role of the electric field and the

Research sponsored by the U.S. Army Tank Command under Interagency Agreement 1969-C101-A1 under Martin Marietta Energy Systems, Inc., contract DE-AC05-84OR21400 with the U.S. Department of Energy. 


\section{DISCLAIMER}

Portions of this document may be illegible in electronic image products. Images are produced from the best available original document. 
applied frequency in sintering can be seen by looking at the power deposition in a material. The amount of power per unit volume that is coupled into the ceramic by electric fields is given by [3]

$$
P=\frac{1}{2} \omega \varepsilon(\tan \delta) E^{2}
$$

This equation shows that the losses are proportional to the frequency $(\omega)$, the loss tangent $(\tan \delta)$, and the square of the electric field $(E)$. In the typical microwave range, the frequency is high $\left(10^{10} \mathrm{~Hz}\right)$, the electric field is low $(<100 \mathrm{~V} / \mathrm{cm})$, and the loss tangent is generally high $\left(10^{-2}\right)$.

The distance that the electric field can penetrate a ceramic is given by [4]

$$
x=\frac{\sqrt{2\left(1+\sqrt{1+\tan ^{2} \delta}\right)}}{\omega \tan \delta \sqrt{\mu_{0} \varepsilon^{\prime}}}
$$

where $x$ is the $e$-folding penetration depth, $\mu_{0}$ is the material permeability (assumed free space), and $\varepsilon^{\prime}$ is the permittivity. An example of the penetration depth as a function of frequency is shown in Fig. 1 for boron carbide $\left(\mathrm{B}_{4} \mathrm{C}\right)$ at $1100^{\circ} \mathrm{C}$ and alumina at $23^{\circ} \mathrm{C}$. Only low frequencies can penetrate high-loss materials (such as $\mathrm{B}_{4} \mathrm{C}$ ). Sintering of relatively large samples of high-loss materials with a uniform electric field can be accomplished when samples have a characteristic length on the order of $0.2 \lambda$. These considerations led to an exploration of the application of rf energy to the sintering process.

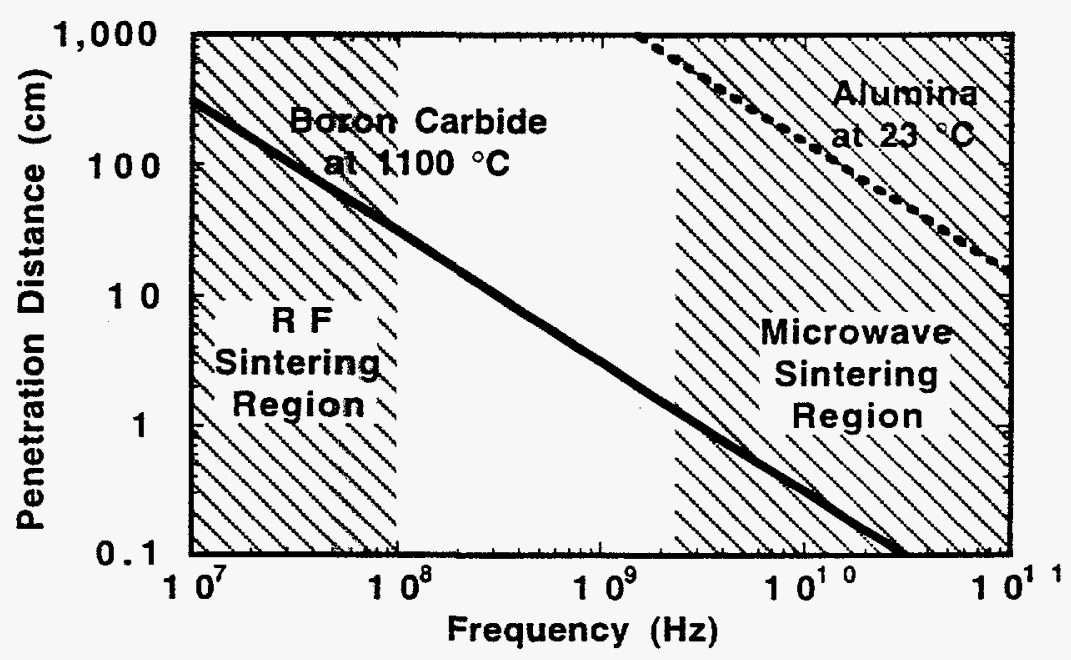

Fig. 1 Depth of electric field penetration as a function of frequency for a low-loss and a high-loss material. 


\section{RF SINTERING}

The advantage of if sintering over microwave sintering is related to the higher electric fields and greater sample penetration depth obtained with sintering at if frequencies. For rf sintering, the frequency is lower $\left(10^{8} \mathrm{~Hz}\right)$, the loss tangent is generally lower $\left(10^{-3}\right)$, and the electric field is higher $(1000 \mathrm{~V} / \mathrm{cm})$. Thus, compared to most microwave techniques, if absorption is reduced by three to four orders of magnitude in the product of frequency and loss tangent, but electric field effects are up to four orders of magnitude higher because the field is 10-100 times greater. Therefore, if sintering has roughly the same total power deposition as microwave sintering but has a much higher electric field and can be used to determine whether the critical component of electromagnetic energy sintering is the strength of the electric field or the value of the excitation frequency. In contrast to microwave sintering, the wavelengths of the rf waves are considerably greater than the dimensions of the sintering cavity. This generally results in a single permissible mode of operation with a uniform electric field, requiring tuning and impedance matching circuitry not commonly found in microwave furnaces.

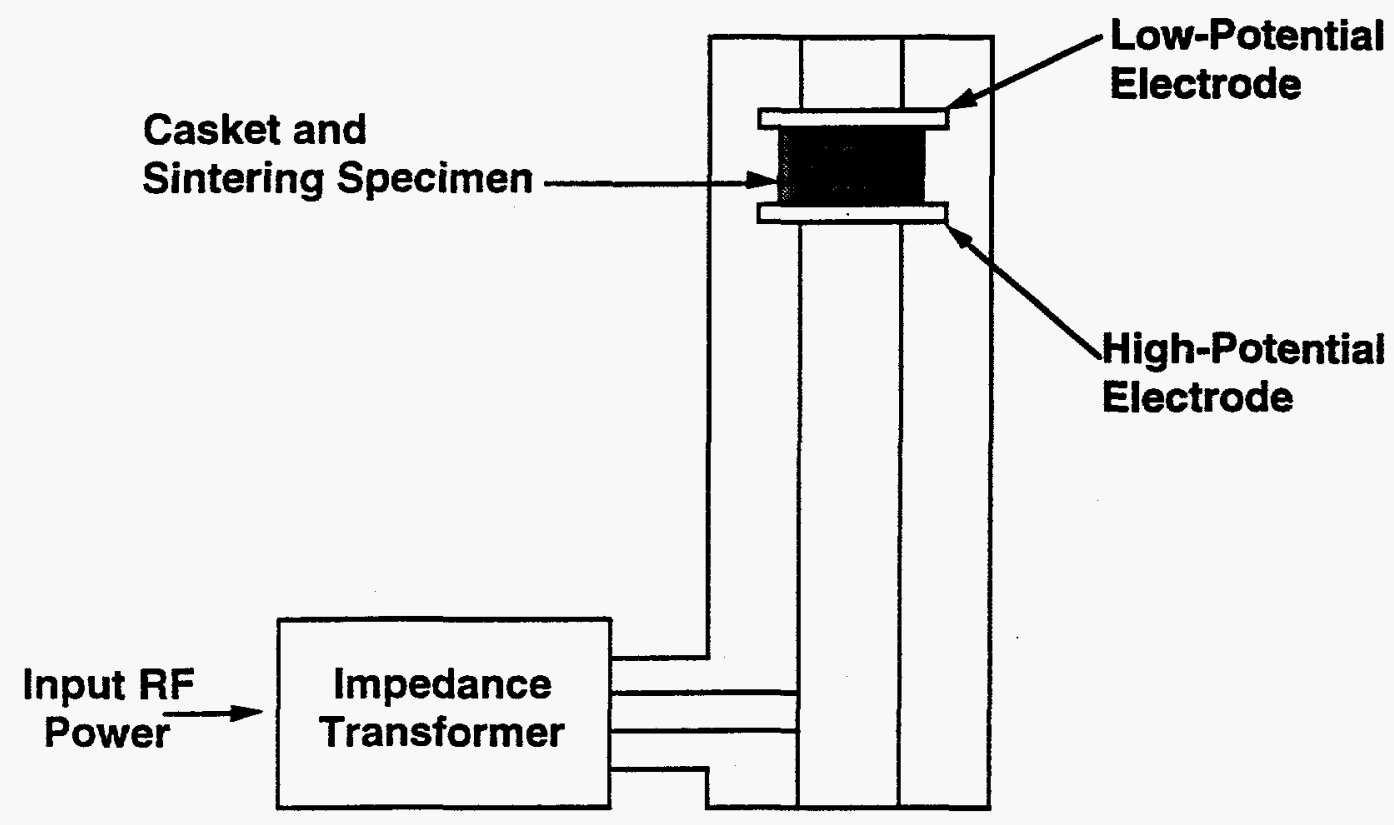

Fig. 2 Schematic of the if sintering furnace. The casket assembly is placed in the high-field region between the electrodes.

A schematic of the rf sintering furnace is shown in Fig. 2. The cavity is composed of a quarter-wave coaxial waveguide resonator, with the center conductor grounded at one end and an electrode placed at the high voltage end. An additional electrode (near ground potential) completes the circuit. The if power is coupled through a variable impedance transformer near the base of the 
cavity, which keeps the cavity tuned and eliminates reflected power during the run. The resonant structure is designed to produce a high electric field at the specimen to be sintered. The sintering specimen is typically packed in insulation inside a casket. The casket assembly is then placed in the high field region between the electrodes and is electrically equivalent to a lossy dielectric between the two plates of a capacitor. Since the cavity is coaxial, an equivalent circuit was analyzed by using a lossy transmission line model that included dielectric losses in the ceramic and resistive losses in the cavity. For a $5 \mathrm{~cm}$ thick lossy dielectric slab placed between the electrodes, calculations have shown that electric fields of $1-5 \mathrm{kV} / \mathrm{cm}$ can exist for a loss tangent variation of $10^{-2}-10^{-4}$ and an input power of $2 \mathrm{~kW}$. An electrostatic analysis of the geometry similar to that shown in Fig. 3 was performed in which a test specimen (dielectric constant, $\varepsilon=8.9$ ) is surrounded by loose dielectric fiber $(\varepsilon=2.3)$. The analysis showed that the field is uniform to within a few percent and is orders of magnitude higher than achievable microwave fields.

To date, two rf sintering chambers have been made. A smaller chamber that operates between $50-55 \mathrm{MHz}$ is used for small samples. The electrodes have a diameter of $13 \mathrm{~cm}$ and a spacing of $5-9 \mathrm{~cm}$. A larger chamber that operates at 35$40 \mathrm{MHz}$ is generally used for larger samples or where larger amounts of insulation are needed. The electrodes have a diameter of $36 \mathrm{~cm}$ and a spacing of $11-15 \mathrm{~cm}$. Several different materials have been processed and are summarized in the next section.

\section{PROCESSING RESULTS}

\section{Zirconia-toughened Alumina}

The density as a function of processing temperature has been determined for the rf sintering of zirconia-toughened alumina (ZTA). This material was chosen so that comparisons could be made to previously published results [5]. The samples were composed of $40 \mathrm{wt} \%$ zirconia (Tosoh TZ-2Y) and $60 \mathrm{wt} \%$ alumina (Sumitomo AKP 50) and prepared as previously described. The mass of the samples were typically $18-20 \mathrm{~g}$. The rf processing frequency was $52 \mathrm{MHz}$, and the processing atmosphere was flowing nitrogen at slightly over 1 atm of pressure.

The samples were arranged in a casket as shown in Fig. 3. They were placed inside a $7.62 \mathrm{~cm}$ diameter, $4.76 \mathrm{~cm}$ thick boron nitride casket and surrounded by a $50 \mathrm{wt} \%$ mixture of alumina and zirconia fiber (Zircar). The casket was placed between the electrodes of the smaller rf sintering furnace. Either graphite or alumina fiberboard plates were placed on both sides of the casket. The temperature of the sample was measured optically by looking at the sample through a sight tube. An Inframetrics 600 Infrared camera was used for measuring temperatures below $1100^{\circ} \mathrm{C}$ and an Ircon 2-color pyrometer was used for temperatures $>1100{ }^{\circ} \mathrm{C}$. The densities were measured using the Archimedes technique in 200-proof ethanol. 


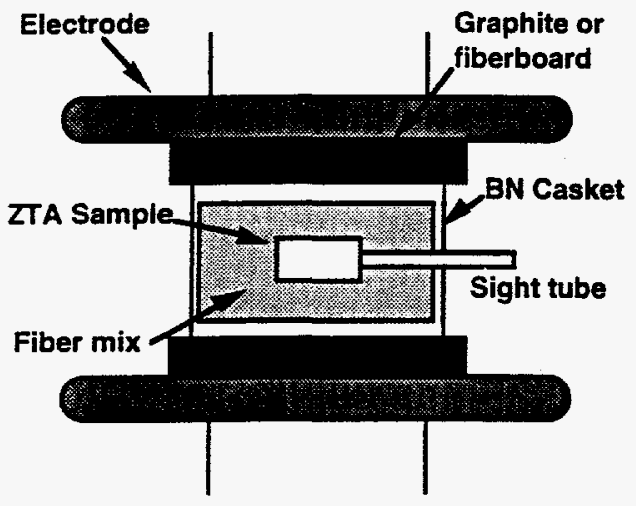

Fig. 3 Arrangement of the casket between the electrodes.

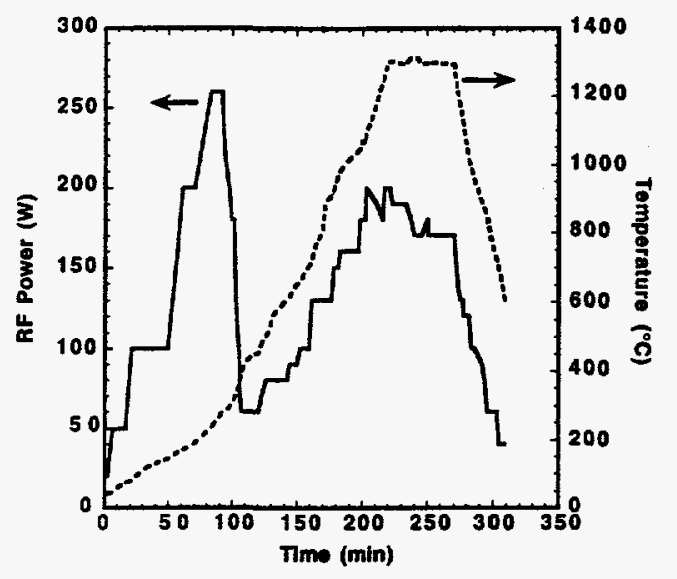

Fig. 4 RF power and sample temp during a ZTA sintering run.

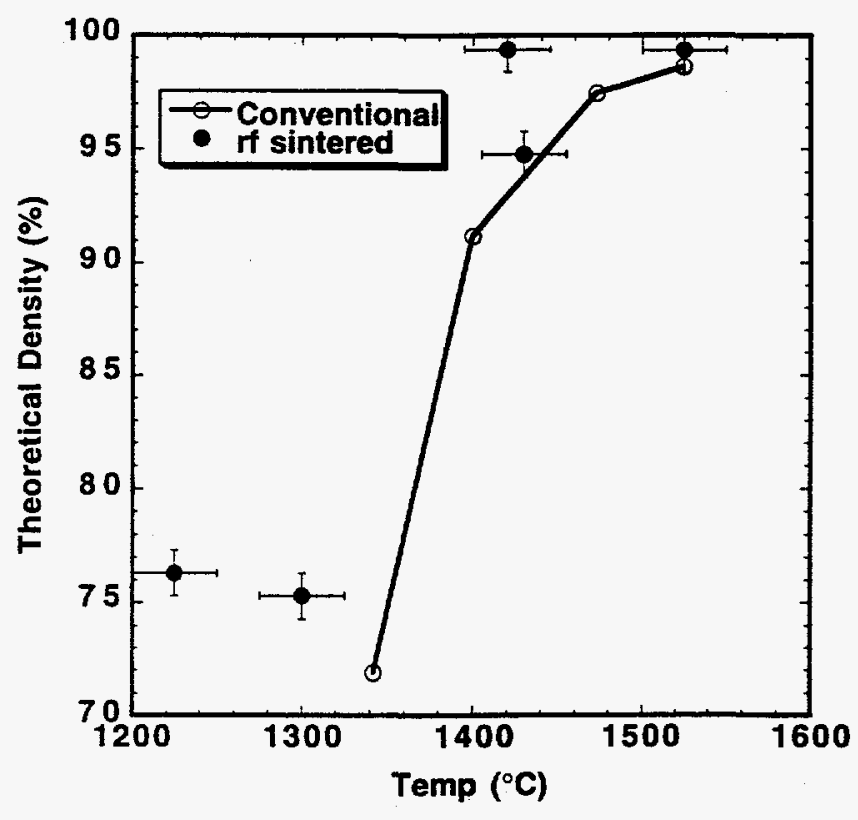

Fig. 5 Density as a function of processing temperature for if sintered ZTA.

Heating rates and power levels were dependent on the temperature of the sample/casket assembly. A plot of $\mathrm{rf}$ power and temperature as a function of time for a typical run is shown in Fig. 4. Initial heating rates of the sample were roughly $2.5^{\circ} \mathrm{C} / \mathrm{min}$ until dielectric relaxation occurred, which was between 250 $350^{\circ} \mathrm{C}$. After this point, the power required to maintain the temperature dropped, 
and the heating efficiency increased significantly. Heating rates increased to roughly $10^{\circ} \mathrm{C} / \mathrm{min}$ up to the desired temperature. The samples were held at the target temperature for 1 hour.

The density as a function of temperature is shown in Fig. 5. For comparison, the sintering curve for conventional processing is also shown in the figure [5]. The uncertainties in the temperature come from the difficulty in focusing the pyrometer through a narrow sight tube. In addition, the center of the sample will be hotter than the edge, and the temperatures shown in the figure should be interpreted as a lower limit for the actual temperature. The dependence of the density on temperature for the if sintered samples is similar to the temperature dependence of the conventionally sintered material. The final densification was $>99 \%$ for the higher temperature samples. Because of the uncertainty of the temperature, however, it is difficult to conclude that there is a significant reduction in the sintering temperature for these samples.

\section{Alumina}

Sintering of alumina has also been achieved using low frequency power at 52 $\mathrm{MHz}$ and $38 \mathrm{MHz}$. The samples were $99.5 \%$ pure alumina (Coors 995 ) and were baked to $800{ }^{\circ} \mathrm{C}$ for 8 hours in air to remove the binder before being sintered. The size and mass of the green bodies varied and ranged from $40 \mathrm{~g}(4.5 \mathrm{~cm} \mathrm{x} 4.5 \mathrm{~cm} \mathrm{x}$ $0.9 \mathrm{~cm})$ to $380 \mathrm{~g}(9.0 \mathrm{~cm} \times 9.0 \mathrm{~cm} \times 1.8 \mathrm{~cm})$. The initial density was about $55 \%$. As with the ZTA, the alumina was processed in a flowing nitrogen atmosphere at slightly over $1 \mathrm{~atm}$.

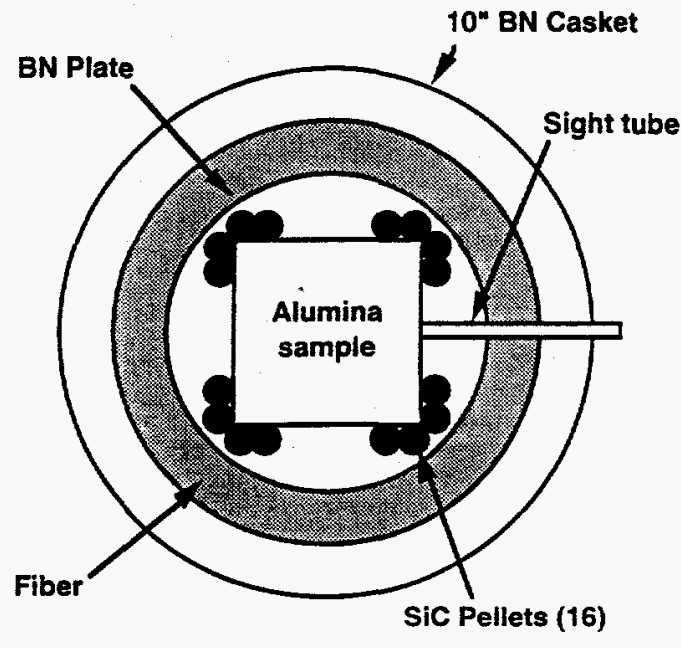

Fig. 6 Arrangement of the sample and casket for alumina runs.

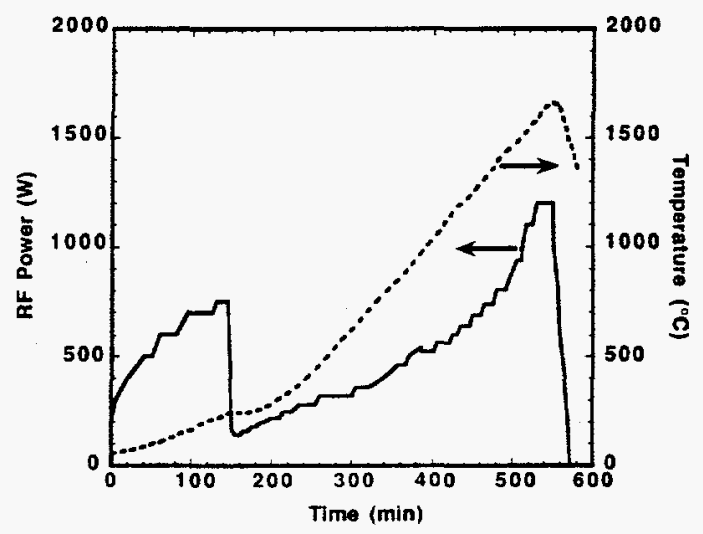

Fig. 7 RF power and sample temp during a $330 \mathrm{~g}$ alumina run.

The samples were arranged in a casket as shown in Fig. 6 . The tiles were placed on a thin $B N$ plate $(0.32 \mathrm{~cm})$ inside a $25.4 \mathrm{~cm}$ diam $B N$ casket $(11.4 \mathrm{~cm}$ high). For the larger samples, a thin layer of alumina powder was used as an 
interface with the BN plate to reduce surface friction. Silicon carbide pellets (1.3 $\mathrm{cm}$ diam, $1.3 \mathrm{~cm}$ thick, $5.3 \mathrm{~g}$ ) were placed at the corners of the sample. The pellets help during the initial heating of the tile and were placed at the corners to reduce the thermal gradient in the sample. A mixture of alumina and zirconia fiber $(50 / 50)$ was used as the insulation, and the temperature was measured through a sight tube as described above.

The power and temperature during a typical run are shown in Fig. 7 for an experiment with a $330 \mathrm{~g}$ sample. Initial heating was slow because of the low loss tangent of the alumina. The presence of the silicon carbide helps in the initial heating phase, but a different arrangement may be needed to optimize the low temperature performance. After relaxation occurs, the heating efficiency increases and the sample readily absorbs power and heats. The heating rate was kept to less than $5^{\circ} \mathrm{C} / \mathrm{min}$ to reduce the chance of cracking in the larger samples. Samples were typically heated to at least $1600^{\circ} \mathrm{C}$ and held there for 30 minutes before cooling. For a $330 \mathrm{~g}$ sample, a power of $1200 \mathrm{~W}$ was needed to heat the sample to $1650^{\circ} \mathrm{C}$. The samples typically densified to $96-98 \%$. Larger samples ( $800 \mathrm{~g}, 4.75 \mathrm{~cm} \mathrm{x} 4.75 \mathrm{~cm}, \times 2.4 \mathrm{~cm}$ greenbodies) are currently being attempted.

Carbides

One of the advantages of rf sintering is the ability of the electric field to penetrate high-loss materials, such as silicon carbide and boron carbide. Both of these materials have been sintered using rf power. Other carbides, such as tungsten carbide and titanium carbide have been either sintered or annealed. The results are summarized in Table $I$. Both silicon carbide and boron carbide have been sintered to $>83 \%$ dense. Accurate temperature measurements for these samples have not been made because of clogging of the sight tube during the experiments. However, the densities that have been obtained are consistent with heating the material to $>2000{ }^{\circ} \mathrm{C}$. An insulation package that can handle temperatures in excess of $2000{ }^{\circ} \mathrm{C}$ is also an issue. Alumina fibers typically fail when the temperature exceeds around $1700^{\circ} \mathrm{C}$. Recent experiments using a combination of zirconia fiber and a mixture of BN power with glassy carbon [6] have shown promising results.

Table I. Carbide materials processed to date.

\begin{tabular}{|l|c|c|c|c|}
\hline \multicolumn{1}{|c|}{ Material } & Process & Temp $\left({ }^{\circ} \mathrm{C}\right)$ & $\%$ Density & \multicolumn{1}{c|}{ Comments } \\
\hline $\begin{array}{l}\text { Silicon carbide } \\
\text { (Cercom) }\end{array}$ & sinter & $\geq 2000$ & 84 & $\begin{array}{l}12.5 \text { g sample (Limited by } \\
\text { current insulation scheme) }\end{array}$ \\
\hline $\begin{array}{l}\text { Boron carbide } \\
(2.5 \text { wt \% C }[7])\end{array}$ & sinter & $>1700$ & 97 & $\begin{array}{l}\text { Repeatability limited by } \\
\text { current insulation scheme }\end{array}$ \\
\hline Zirconia & sinter & 1410 & 98.4 & 9.2 g sample \\
\hline Titanium carbide & anneal & 1500 & - & 31 g sample \\
\hline $\begin{array}{l}\text { Tungsten carbide } \\
(6 \text { wt \% Co) }\end{array}$ & sinter & 1500 & 97 & 14 g sample \\
\hline
\end{tabular}




\section{SUMMARY}

We have demonstrated the use of low frequency $(<55 \mathrm{MHz})$ rf power to sinter ceramics. Sintering with lower frequencies than microwaves has the advantage of being able to penetrate large or high-loss materials with higher electric fields. Because the if wavelengths are longer than the dimensions of the furnace, the mode of operation can be controlled to ensure nearly uniform electric fields in the region of interest. Processing to temperature up to $1700^{\circ} \mathrm{C}$ is now routine, and progress is being made to extend the temperature range to $>2000{ }^{\circ} \mathrm{C}$. The sintering of ZTA and large (>330 g) alumina samples (without cracking) has been accomplished, along with the sintering and/or annealing of high-loss carbide materials, such as boron carbide and silicon carbide. This low frequency operating regime offers a unique opportunity to determine the effects of sintering due to electric field interactions with materials.

\section{REFERENCES}

[1] Microwaves: Theory and Application in Materials Processing II, edited by D. E. Clark, W. R. Tinga, and J. R. Laia, Jr., (Ceramic Transactions 36), American Ceramic Society, Inc., Westerville, Ohio, 1993.

[2] Microwave Processing of Materials IV, edited by M. F. Iskander, R. J. Lauf, and W. H. Sutton, MRS Symp. Proc. Vol. 347 (Materials Research Society, Pittsburgh, Pennsylvania, 1994).

[3] W. H. Sutton, "Microwave Processing of Ceramic Materials," Ceram. Bull. 68 (2) 376-386 (1989).

[4] A. R. von Hippel, "Descriptions of Dielectrics by Various Sets of Parameters," in Dielectric Materials and Applications, edited by A. R. von Hippel, Technology Press of MIT/John Wiley \& Sons, New York, 1954, p. 12.

[5] H. D. Kimrey, J. O. Kiggans, M. A. Janney, and R. L. Beatty, "Microwave Sintering of Zirconia-Toughened Alumina Composites," MRS Symp. Proc. Vol. 189 (Materials Research Society, Pittsburgh, Pennsylvania, 1991) 243.

[6] C. E. Holcombe, N.L. Dykes, and M.S. Morrow, "Thermal insulation for high-temperature microwave sintering operation and method thereof," U.S. Patent Application in Progress (1993).

[7] C.E. Holcombe and N.L. Dykes, "Ultra High-Temperature Microwave Sintering," Ceramics Transactions 21 (American Ceramic Society, Inc., Westerville, Ohio, 1991) 375.

\section{DISCLAIMER}

\footnotetext{
This report was prepared as an account of work sponsored by an agency of the United States Government. Neither the United States Government nor any agency thereof, nor any of their employees, makes any warranty, express or implied, or assumes any legal liability or responsibility for the accuracy, completeness, or usefulness of any information, apparatus, product, or process disclosed, or represents that its use would not infringe privately owned rights. Reference herein to any specific commercial product, process, or service by trade name, trademark, manufacturer, or otherwise does not necessarily constitute or imply its endorsement, recommendation, or favoring by the United States Government or any agency thereof. The views and opinions of authors expressed herein do not necessarily state or reflect those of the United States Government or any agency thereof.
} 